\title{
Soy protein: The next antihypertensive agent?
}

He J, Songfeng G, Xigui W, Jichun C, Xiufang D, Jing C, et al. Effect of soybean protein on blood pressure: a randomized, controlled trial. Ann Intern Med 2005;143:1-9.

Background: The prevalence of hypertension continues to increase dramatically in developing countries. Worldwide, an estimated 1 billion individuals are hypertensive; there is therefore great interest in identifying the lifestyle factors (e.g., weight and salt and alcohol intake) that affect blood pressure. Dietary potassium supplementation, for example, has been shown to reduce blood pressure in patients with either high-normal pressure or hypertension. Observational studies have shown that dietary vegetable (but not animal) protein is associated with lower blood pressures; but until now, the results of randomized trials have been inconclusive.

Design: This double-blind, controlled trial in the People's Republic of China was designed to test the efficacy of soybean protein supplements compared with a placebo. It involved 302 people 35-64 years of age with an initial untreated blood pressure of $130-159 \mathrm{~mm} \mathrm{Hg}$ systolic or 80-99 $\mathrm{mm} \mathrm{Hg}$ diastolic, or both. Pressures were measured on the right arm with a randomzero sphygmomanometer; the data recorded were averages of 9 pressure readings taken over 3 visits within a single week. Demographic characteristics of the patients enrolled in the 3 participating clinical centres (in Beijing, Xiulo and Wuhan) were all similar. Randomization was stratified by clinical site.

Participants assigned to the intervention group $(n=150)$ rer ceived cookies containing a $40-\mathrm{g}$ supplement of isolated soybean protein every day for 12 weeks; during the same period, those in the control group $(n=152)$ received wheat cookies including $40 \mathrm{~g}$ of complex carbohydrate. Nutritional contents were simi- lar except for dietary protein (49.0 g v. $12.9 \mathrm{~g}$, respectively) and carbohydrates (64.8 $\mathrm{g} \mathrm{v}$. $95.3 \mathrm{~g})$. The primary outcomes were changes in blood pressure between baseline and week 12 of follow-up. Analysis included the assessment of outcomes on an intention-to-treat basis.

Results: After 12 weeks, systolic blood pressures in the intervention group dropped by a mean of 4.31 (95\% confidence interval [CI] 2.11-6.51) mm Hg more than in the control group; diastolic pressures, by 2.76 (95\% CI 1.35-4.16) mm Hg more. Side effects were unremarkable and similar in both groups.

In subgroup analyses, the blood pressure decrease among hypertensive patients who ate the soybean cookies was significant: 7.88 (95\% CI 4.66-11.1) $\mathrm{mm} \mathrm{Hg}$ systolic and 5.27 (95\% CI 3.05-7.49) $\mathrm{mm} \mathrm{Hg}$ diastolic. Pressures also declined, but not significantly, among those with high-normal blood pressure.

Commentary: In this study, people with hypertension achieved significant blood pressure reductions over 12 weeks with the addition of $40 \mathrm{~g} / \mathrm{d}$ of isolated soybean protein to their diet. Whether these results are applicable to a North American population, with its different dietary protein intake, is unclear.

A second unsettled question is whether blood pressures were reduced because of soybean protein or isoflavones (of which $76.4 \mathrm{mg} / \mathrm{d}$ was provided in the soy cookies). Soy isoflavones are phytoestrogens, a class of nonsteroidal estrogens that has been shown to lower blood pressure by improving systemic arterial elasticity. The study's authors did not examine the mechanism by which dietary protein may influence blood pressure.

Prevention is a prominent motivation for dietary change, and this study does not help to settle whether intake of soy protein can prevent hypertension. And although the addition of soy protein in this study resulted in no adverse events, it is not without long-term risk: observational studies in Singapore ${ }^{1}$ and Shanghai ${ }^{2}$ showed a statistically significant increased risk of bladder cancer among people who consume soy. The weakness of the evidence that soy protein is beneficial to people with blood pressures in the high-normal range shows that longer-term studies are required before practical recommendations can be made. ${ }^{3}$

Practice implications: Soybean supplementation may be considered for patients with mild hypertension who do not wish to take medication. Although this study did not show a definite benefit among patients with high-normal blood pressure, better eating habits, such as an adherence to the DASH (Dietary Approaches to Stop Hypertension) diet, eventually may reduce several cardiovascular risk factors. As to the role of soy in one's diet, it remains a topic for further investigation.

Ana M. Cartagena

University of Manitoba

Class of 2008

Winnipeg, Man.

\section{References}

1. Sun CL, Yuan JM, Arakawa K, Low SH, Lee HP, Yu MC. Dietary soy and increased risk for bladder cancer: the Singapore Chinese Health Study. Cancer Epidemiol Biomarkers Prev 2002;11:1674-7.

2. Sun CL, Yuan JM, Wang XL, Gao YT, Ross RK, Yu MC. Dietary soy and increased risk for bladder cancer: a prospective cohort study of men in Shanghai, China. Int 7 Cancer 2004; 112:319-23.

3. Cutler JA, Obarzanek E. Nutrition and blood pressure: Is protein one link? Toward a strategy of hypertension prevention [editorial]. Ann Intern Med 2005;143:74-5. 